
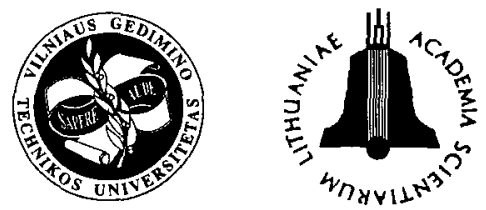

ISSN $1392-3730$

JOURNAL OF CIVIL ENGINEERING AND MANAGEMENT

http:/www.vtu.lt/english/edition

2002, Vol VIII, No 2, 117-120

\title{
CRACK FORMATION IN VACUUM CONCRETE
}

\author{
Grigory Yakovlev', Nikolai Khokhriakov ${ }^{2}$ \\ ${ }^{1}$ Dept of Geothechnic and Buildings Materials. Izhevsk State Technical University (IzhSTU), \\ Studencheskaya 7,Izhevsk, Russia.E-mail: jakowlew@udm.net \\ ${ }^{2}$ Laboratory of Molecular Modelling, Physical Faculty, Udmurt State University, 426034, \\ Universitetskaya, 1, Izhevsk, Russia
}

Received 12 Nov 2001; accepted 05 Febr 2002

\begin{abstract}
The reasons of crack formation in vacuum concrete floors with reinforcing mineral wear-resistant coating were investigated. The main reasons of crack formation are connected with low concrete strength due to the lack of water for cement hydration, the absence of shrinkage seams in floor structure, wrong reinforcement and excess thickness of strengthening mineral coating of concrete floor which initiates the crack formation.

At the concrete thickness $150 \mathrm{~mm}$, the depth of crack spreading was $115 \mathrm{~mm}$, the concrete strength in kerns - 14.2-24.8 $\mathrm{MPa}$ instead of $30 \mathrm{MPa}$ as planned, and the concrete macrostructure had the signs of lamination. Besides, an air clearance up to $4 \mathrm{~mm}$ in size was found between the foundation and concrete floor.

The reinforcement skeleton structure in concrete floors did not envisage the possibility of horizontal displacement of concrete coating in the square limited by deformation seams, and the deformation seams did not penetrate into the depth planned eliminating their formation during concrete hardening.

X-ray phase analysis of fresh hardening coating of concrete surface showed the presence of ettringite in it, and nonhydrated Portland cement minerals prevailed in the structure of concrete solution resulting in insufficient strength of the concrete hardened.

Thus, due to the considerable heterogeneity of vacuum concrete structure and properties by thickness, the presence of the initiator of crack formation in the concrete upper layer (ettringite) and wrong reinforcing the formation of uneven shrinkage phenomena in hardening cement takes place resulting in crack net formation in the upper stretched concrete area.
\end{abstract}

Keywords: concrete floor, reinforcement, etthryngit, X-ray phase analysis.

\section{Introduction}

The possible reasons of cracking of hardening cement concrete are widely discussed in engineering literature and are in most cases explained by drying shrinkage of concrete [1-3]. The theoretical research works are known [4-6] concerned with modelling of formation and development of crack in such materials. For a decrease of probability of cracking the technological and constructive methods are proposed, such as introduction of a dispersed rebar [7-10] and usage of shrinkage seams [11]. The registration of fractures formed was carried out by methods of non-destructive testing (NDT). A literature search using in NDT database revealed a number of possible NDT techniques [12], including ultrasonic (ultrasonic [13] and acoustic emission [14, 15]), thermography [16] and X-ray imaging process [17].

The cracks formed are usually exposed to repair by polymeric compositions injection [18].

In the present article we investigate reasons of formation of many cracks formed during hardening of wearresistant concrete non-dusting floor coating of $150 \mathrm{~mm}$ thick arranged in industrial premises. The interrelation of location character of cracks with the floor vertical deformation was observed. The use of the floors was stopped till finding out the reason of crack formation.

The floor construction included the coating of monolithic concrete with the subsequent vibration and vacuum compaction of the surface layer. To improve physicalmechanical characteristics of the concrete surface, a reinforcing cement-mineral composition was applied twice with the following mechanical sweating of the surface.

The bottom level of the concrete coating was reinforced by flat net from reinforcing rods of periodic profile with diameter of $10 \mathrm{~mm}$ and rod step of $200 \times 200 \mathrm{~mm}$.

To organise control joints in concrete coating, $2 \mathrm{~cm}$ deep cuts were done by diamond discs, the distance between the cuts being $6000 \mathrm{~mm}$.

\section{Methods of research}

The concrete mechanical characteristics were determined while testing core samples drilled from the floor concrete coating by a hydraulic press P-250. At the same 
time the concrete strength was controlled by non-destructive method using Schmidt sclerometer.

The crack size was determined by microscope-magnifier MPB-2 with multiplying factor $0,1 \mathrm{~mm}$. The concrete was cleaned in the crack area and the cracks were wiped with acetone for better visualisation.

The floor concrete coating deformations were determined using laser levelling instrument "Limka-Zenit" by geometric levelling method.

Phase composition of cement stone in concrete composition was determined using X-ray diffractometer of general application DRON-3. The minerals in cement stone composition were identified according to the data in the reference book $[19,20]$. Differential-thermal analysis was carried out by the thermograph of "MOM" company.

\section{Results and discussion}

The floors, when examined in the process of their arrangement in October 1999, were without cracks. During the examination in February 2000 the concrete coating had numerous cracks, the distance between them being $1,5-2,5$ meters, the depth up to $135 \mathrm{~mm}$ and dissection value up to $1,2 \mathrm{~mm}$ (Fig 1).

The concrete strength according to non-destructive test was $20,7 \mathrm{MPa}$ and this did not correspond with the designed grade of concrete B 30 .

When the core was removed, there was an air clearance up to $4 \mathrm{~mm}$ between the floor base and the concrete coating (Fig 2).

Under the concrete coating there was a hydro-insulating material in the form of polyethylene film which eliminated the possibility of adhesion of concrete being laid with covering plates and increased the possibility of their separate work.

As seen from the profile of concrete coating surface in crack area (Fig 3), there is a direct correlation between the crack location and its elevation. Cracks, as

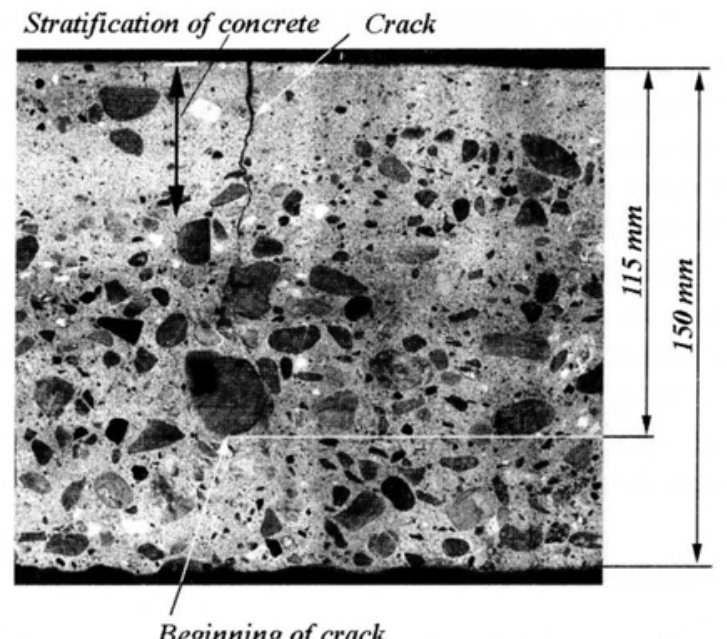

Fig 1. Character of crack propagating in concrete coating

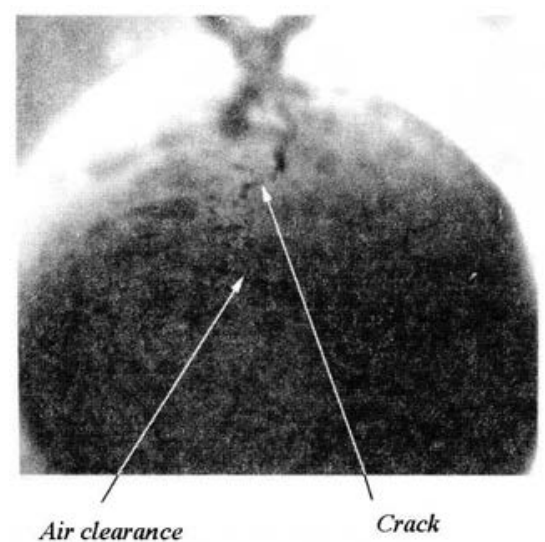

Fig 2. Air clearance between floor base and concrete coating

a rule, are located on the profile top when a core is drilled out through the crack, the air clearance between the base and concrete coating is observed. Concrete mixture lamination during laying led to the increase of cement stone volume in the upper level of concrete. X-ray phase analysis of cement stone composition also showed a considerable volume of amorphous component which is the major reason for concrete shrinkage. Thus, concrete shrinkage in the upper level of the coating and practically the absence of shrinkage phenomena in bottom reinforced level of concrete coating resulted in the formation of uneven tensions along the coating thickness. All the above

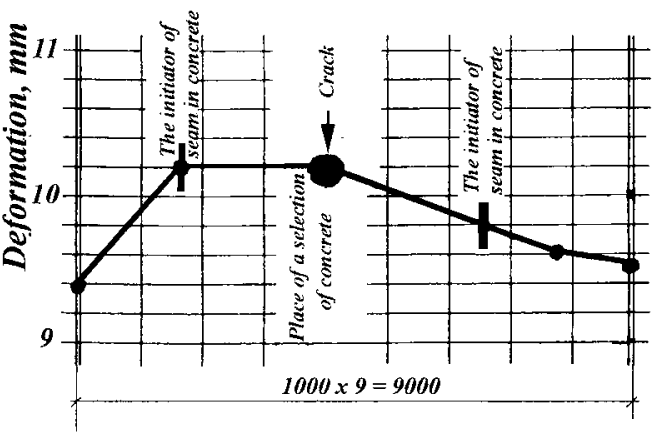

Fig 3. Concrete coating profile in crack area

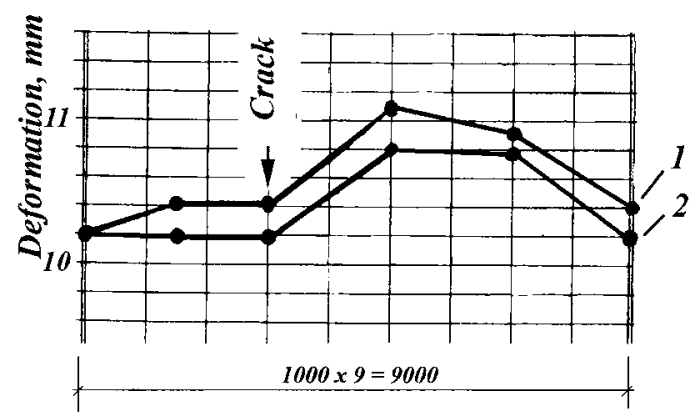

Fig 4. Concrete floor profile across the crack: 1) without load; 2) the floor is loaded by 1,2 ton technological transport 


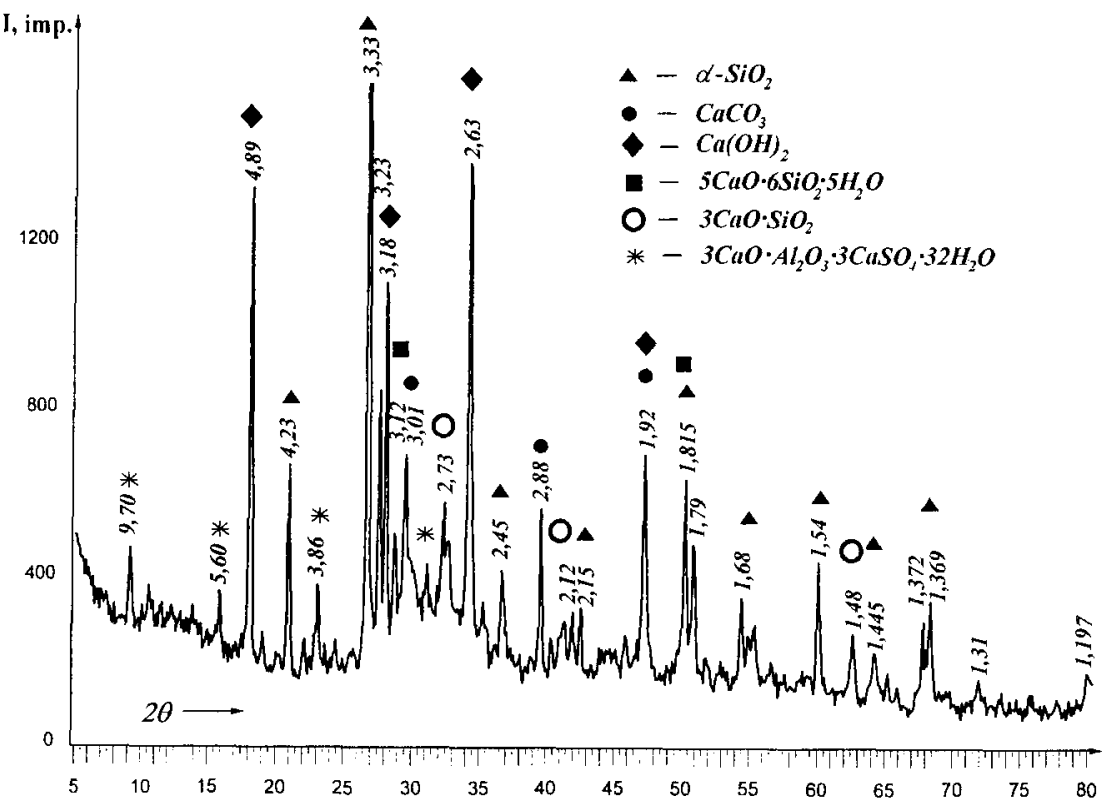

(in excess for normal cement hardening) which promotes ettringite formation. It is possible that at a rather low determined concrete strength ettringite initiates crack formation at the beginning of concrete hardening [21]

Differential-thermal analysis of concrete mixture solution part (Fig 6) showed three vivid endothermic effects directly connected with differential thermogravimetric curve. The total sample mass loss does not exceed $12,2 \%$. Taking the availability of free water $(3,1 \%)$ into consideration, the total quantity of bound water equals $8 \%$ additionally confirming incomplete cement hy-

Fig 5. X-ray diffractogram of cement stone in crack area

indicates that cracks are formed due to the concrete surface bending as a result of uneven shrinkage in hardening concrete.

The profiles of concrete coating surface along the line perpendicular to the crack obtained during levelling without load and using 1,2 ton technological transport are shown in Fig 4 . When the technological transport was moving over the crack, the laser levelling instrument showed the beam deviation from the initial direction. This indicates obvious floor deformations when additional load is applied.

Floor deformation is impossible due to the presence of air clearance under the concrete coating shown in Fig 2. The floor deformations indicated are reversible and this confirms tense condition of concrete coating owing to reinforced net in the bottom (pressed) layer. Consequently, the process of cracks opening and closing is inevitable under the process of concrete coating service conditions leading to their crack propagation.

The X-ray phase analysis (Fig 5) showed the presence of non-hydrated alite together with calcium hydroxide, tobermorite gel and quartz. Alite presence shows that as a result of concrete drying there is obviously a lack of water for cement hydration, thus the concrete is not strong enough. There are also reflections corresponding to calcium carbonate. The availability of sufficient volume of amorphous phase in concrete composition is characteristic ("top crust" in the area $2 \theta=26-38^{\circ}$ ), which as it has been already mentioned, increases shrinkage in hardening concrete.

Images corresponding to calcium hydrosulphoaluminate (ettringite) which is formed in concrete surface layer due to sealing layer introduction are well registered. Sealing composition contains dihydrate gypsum dration in concrete composition.

In accordance with the manufacturing technology of floor concrete coating it is assumed that deformation seams are formed during shrinkage according to initiating principles. In reality it is not possible in the object being investigated due to the small cut depth and uniform reinforcement in the bottom layer of concrete coating. The cut is $2 \mathrm{~cm}$ deep instead of the fixed one-third from the total thickness of concrete coating equal to 5 $\mathrm{cm}$ (Fig 7).

The investigated process of crack formation can be stopped and stabilized if the concrete coating is cut into

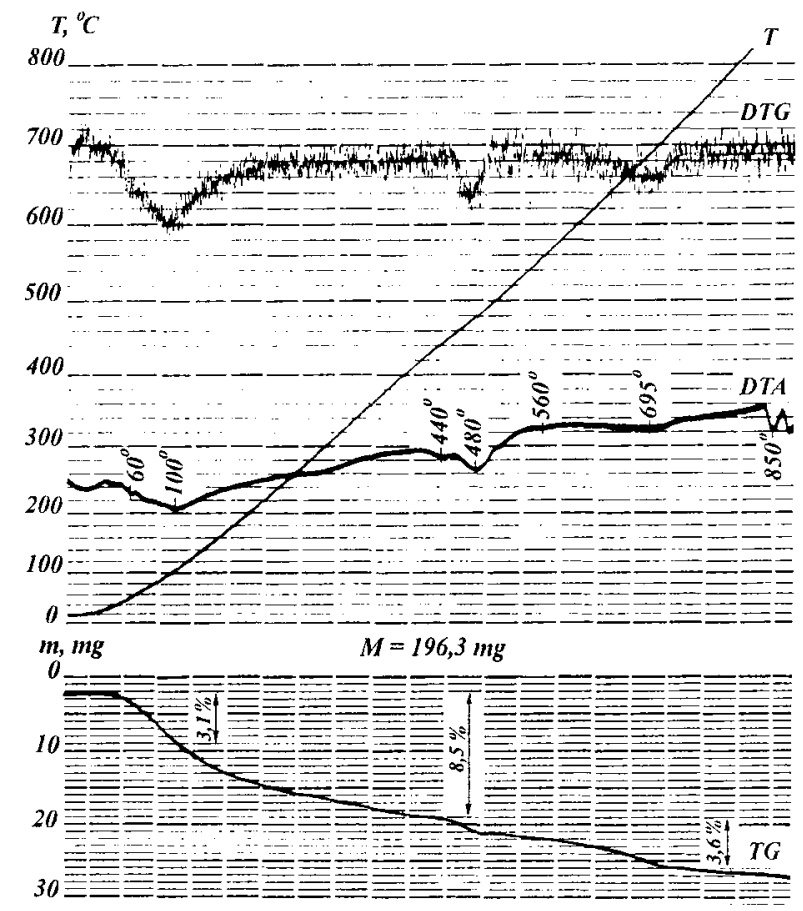

Fig 6. Thermogram of concrete mixture solution part 


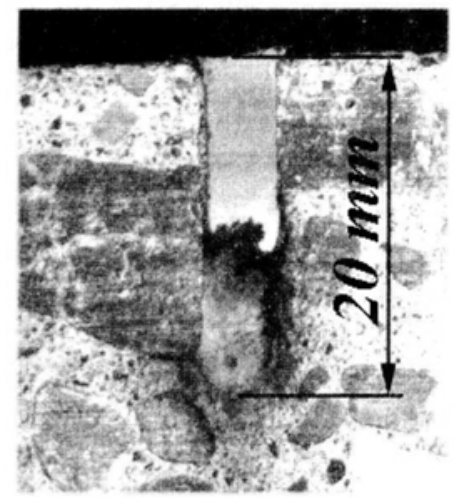

Fig 7. Initiating cut inside the concrete, the marker shows the cut depth

separate cards via the overall depth (including reinforced net) for developing deformation seams. It will allow to remove the concrete tension and eliminate crack formation.

Thus, according to the above data, the main reasons for crack formation of floor concrete coating are uneven shrinkage phenomena in floor concrete coating which are unable to relax due the absence of deformation seams.

\section{Conclusions}

1. Vacuum concrete having additional mineral coating from hardening layer requires long-term protection against drying from the surface to eliminate an intensive water loss. Due to the water shortage in concrete hardening is stopped resulting in the strength decrease. The predominance of cement stone in concrete composition increases shrinkage in hardening concrete due to a considerable volume of amorphous stage at the excess of cement dough and leads to crack growth.

2. To avoid the crack spreading, deformation seams must be envisaged in floor construction for the whole thickness of concrete coating. The reinforcement rods must allow horizontal movements of concrete coating in the framework of card limited by deformation seams.

3. One of the possible reasons of initiation of cracks formation can be the development of tension during hardening of the upper strengthening layer due to the formation of calcium hydrosulphoaluminate (ettringite).

\section{References}

1. Friede $H$. Mathematical estimotimotion splitting tendency of the fresh concrete. Concrete (Beton), 1982, No 7, p. 261-266 (in German).

2. Mueller $\mathrm{G}$. The cracks in reinforced concrete construction. Concrete (Beton), 1989, No 1, p. 13-18 (in German).

3. Huth W. The new gudety concrete without split. Cement + Concrete (Zement + Beton), 1996, No 1, p. 32-38 (in German).
4. Brito V. P., Gomes M. A. F., Souza F. A. O., Adhikari S. K. Diversity of fragments in the collapse of brittle solids. Physica A: Statistical and Theoretical Physics, Vol 259, 1998, No 3-4, p. 227-234.

5. Zapperi S., Ray P., Stanley H. E., Vespignani A. Analysis of damage clusters in fracture processes. Physica A: Statistical Mechanics and its Applications, Vol 270, 1999, No 1-2, p. 57-62.

6. Borodich F. M. Some fractal models of fracture. J. Mech. Phys. Solids, Vol 45, 1997, No 2, p. 239-259.

7. Lin Z., Li V. C. Crack bridging in fiber reinforced cementitious composites with slip-hardening interfaces. $J$. Mech. Phys. Solids, Vol 45, 1997, No 5, p. 763-787.

8. Barros J. A. O., Sena Cruz J. Fracture Energy of Steel Fiber-Reinforced Concrete. Mechanics of Composite $\mathrm{Ma}$ terials and Structures, Vol 8, 2001, No 1, p. 29-45.

9. Feldman D., Denes F., Zeng Z., Denes A. R., Banu D. Polypropylene fiber-matrix bonds in cementitious composites. Journal of Adhesion Science and Technology, Vol 14, 2000, No 13, p. 1705-1721.

10. Barros J. A. O., Figueiras J. A. Flexural Behaviour of SFRC: Testing and Modelling. J. Mater. Civil Eng., Vol 11, 1999, No 4, p. 331-339.

11. The cement conference. The craks in the concrete. Concrete (Beton), 1999, No 3, p. 136-140 (in German).

12. Tarricone $\mathrm{P}$. Inspection goes high tech. Civil Engineering, Vol 61, 1995, No 5, p. 38-41.

13. Ogura Y., Miyajima T., Takishita T., Ohtake K., Akutsu Y. Measurement of crack depths in concrete. In: Proceedings of the $12^{\text {th }}$ World Conference on Non-Destructive Testing, Amsterdam, Vol 2, 1989, p. 1249-1254.

14. Yuyama S., Li Z.-W., Yoshizawa M., Tomoliyo T., Uomoto T. Evaluation of fatigue in reinforced concrete slab by acoustic emission. NDT\&E International, Vol 34, 2001, No 3, p. 381-387.

15. Smith R. L., Crook M. J. The non-destructive detection and mapping of ASR cracking in concrete. Transport and Road Research Laboratory, Crowthorne (UK), TRRL-CR156, ISSN-0266-7045, 1989. 38 p.

16. Titman D. J. Applications of termography in non-destructive testing of structures. NDT\&E International, Vol 34, 2001, No 2, p. 149-154.

17. Tillack G.-R., Nockemann C., Bellon C. X-ray modelling for industrial applications. NDT\&E International, Vol 33, 2000, No 7, p. 481-488.

18. Asendorf K. The lar injection in cracks. Concrete (Beton), 1988, No 1, p. 11-17 (in German).

19. ASTM Card File (Diffraction Data Cards), Philadelphia, Ed. ASTM, 1989.

20. Binders, ceramic and glass-ceramic: structure and properties: Reference book / V. S. Gorshkov, W. G. Saveliyev, A. V. Abakoumov. Moscow: Stroyizdat, 1994. 576 p.

21. Taylor H. F. W. Cement Chemistry, Academic Press Ltd, London, 1990. 